\title{
Enraizamento de estacas de Sebastiania schottiana Müll. Arg.
}

\author{
Rooting of Sebastiania schottiana Müll. Arg. cuttings
}

\author{
Eduardo Garcia Frassetto ${ }^{I}$ Elci Terezinha Henz Franco ${ }^{I}$ Paula Kielse $^{\mathrm{I}}$ \\ Vanessa Fiad Martins do Amaral ${ }^{I}$
}

\section{RESUMO}

O pouco domínio dos processos envolvidos no enraizamento de estacas de diversas espécies florestais tem sido um fator limitador para a produção de mudas via propagação vegetativa, impedindo possiveis ganhos econômicos e ecológicos nas atividades de reflorestamento $e$ recuperação de áreas degradadas. O objetivo deste estudo foi verificar o potencial de enraizamento de estacas de Sebastiania schottiana, submetidas a diferentes doses e tempos de imersão em produto comercial Orgasol ${ }^{\circledR}$ FTS (composto de aminoácidos e micronutrientes). Estacas basais, medianas e apicais tiveram suas bases imersas em Orgasol ${ }^{\circledR}$ FTS nas doses de 0; 5; 10 e $15 \mathrm{~mL} \mathrm{~L} \mathrm{~L}^{-1}$, durante 1 minuto. $O$ delineamento experimental foi realizado em blocos ao acaso, com três repetições de 20 estacas por parcela. Aos 75 dias, avaliou-se a porcentagem de estacas enraizadas, o comprimento e diâmetro da raiz mais longa. Em um segundo experimento, estacas basais e medianas foram tratadas em $15 \mathrm{~mL} L^{-1}$ do produto, durante $0,15,30$ e 45 minutos. $O$ delineamento experimental foi realizado em blocos ao acaso, com três repetições e 20 estacas por parcela. Aos 150 dias, avaliou-se a porcentagem de estacas enraizadas, massa seca das raizes e o comprimento e diâmetro da raiz mais longa. No primeiro experimento, o aumento da dose do produto promoveu um maior potencial de enraizamento em todos os tipos de estacas, com maior porcentagem de estacas enraizadas no tratamento com $15 \mathrm{~mL} L^{-1}$ do produto. No segundo experimento, os maiores potenciais de enraizamento foram observados em estacas basais e medianas tratadas com $15 \mathrm{~mL} L^{-1}$ do produto, por 45 minutos. $O$ uso do produto comercial Orgasol ${ }^{\circledR}$ FTS favoreceu a indução de raízes adventicias em estacas de Sebastiania schottiana.

Palavras-chave: Sarandi, propagação vegetativa, aminoácidos, raizes adventícias, micronutrientes.

\begin{abstract}
The aim of this study was to verify the rooting potential of Sebastiania schottiana cuttings treated with different doses and immersion times in Orgasol ${ }^{\circledR}$ FTS (composed with amino acids and micronutrients). In a first trial, basal, median and apical cuttings had their bases immersed in Orgasol ${ }^{\circledR}$ FTS at levels of 0,5,10 and $15 \mathrm{~mL} \mathrm{~L} \mathrm{~L}^{-1}$, for 1 minute. The experimental design was in random blocks, with three replicates and 20 cuttings per plot. At 75 days, the rooted cuttings percentage, the length and diameter of the longest root were evaluated. In a second trial, basal and median cuttings were treated for 0 , 15, 30 and 45 minutes in $15 \mathrm{~mL} \mathrm{~L} L^{-1}$ of Orgasol ${ }^{\circledR}$ FTS. The experimental design was in random blocks, with three replicates of 20 cuttings per plot. At 150 day, the rooted cuttings percentage, dry roots mass and the length and diameter of the longest root were evaluated. In the first trial, higher levels of product was beneficial to rooting, it was observed the largets rooted cuttings percentage in the treatment with $15 \mathrm{~mL} \mathrm{~L}^{-1}$ of product. In second trial, the higher rooting potential was observed in the basal and median cuttings treated by 45 minutes in $15 \mathrm{~mL} \mathrm{~L} L^{-1}$ of product. The use of orgasol ${ }^{\circledR}$ FTS promotes adventitious roots in Sebastiania schottiana cuttings.
\end{abstract}

Key words: Sarandi, vegetative propagation, amino acids, adventitious roots, micronutrients.

\section{INTRODUÇÃO}

Pertencente à família Euphorbiaceae, Sebastiania schottiana Müll. Arg. é uma espécie florestal arbustiva que atinge $3,5 \mathrm{~m}$ de altura, com fuste de pouca espessura, ramos longos e ramificados

\footnotetext{
'Programa de Pós-graduação em Engenharia Florestal, Universidade Federal de Santa Maria (UFSM), 97105-900, Santa Maria, RS, Brasil. E-mail: paulakielse@yahoo.com.br. *Autor para correspondência.
} 
(MARCHIORI, 2000). É uma planta adaptada à reofilia, bastante resistente às variações extremas de umidade ou seca; dispondo de um denso sistema radicial, com caules rijos e flexíveis, características que propiciam o seu sucesso no controle de erosões das margens de rios, deslizamentos, desmoronamentos e transporte de sedimentos (REITZ, 1988). É uma espécie de difícil reprodução via sexuada, em decorrência do amadurecimento irregular dos frutos, dificultando a coleta das sementes quando estes atingem o seu ponto de máxima maturidade fisiológica (DESCHAMPS \& PINTO, 1995). Esse fato tem determinado a estaquia como um método alternativo de produção de mudas dessa espécie.

A propagação vegetativa por estaquia é uma técnica simples e de grande praticidade, contudo, a posição de coleta da estaca no ramo pode provocar grande variação no potencial de enraizamento (HARTMANN et al., 2002) e influenciar no desenvolvimento e na sobrevivência das plantas (GONDIM et al., 2001). No enraizamento de espécies florestais, observa-se que, por uma questão de maturidade fisiológica, estacas obtidas da base da copa possuem maior potencial de enraizamento se comparadas às retiradas da parte superior (HARTMANN et al., 2002). Além da escolha da estaca ideal, faz-se necessário o estudo de substâncias que possam otimizar o processo de formação de raízes adventícias, possibilitando o aumento da quantidade e qualidade das mudas, com menores custos de produção. A utilização de aminoácidos tem sido uma prática comum na agricultura, pelos inúmeros benefícios que essas substâncias orgânicas proporcionam às plantas (BRANDÃO, 2007). Contudo, estudos com a utilização de aminoácidos ainda são escassos, especialmente como estimuladores do enraizamento em estacas.

O Orgasol ${ }^{\mathbb{R}}$ FTS é um composto orgânico natural líquido que contém aminoácidos como ingredientes ativos, associados a $0,5 \%$ de boro (B), $0,2 \%$ de cobalto ( $\mathrm{Co}$ ), $1,0 \%$ de ferro (Fe), $0,8 \%$ de molibdênio (Mo) e 1,5\% de zinco ( $\mathrm{Zn}$ ). O produto fornece aminoácidos de base fenólica e proteínas solúveis que ativam o metabolismo da planta, auxiliam na síntese de hormônios, na circulação da seiva e no transporte de nutrientes (RSA, 2006), além de apresentar menor custo de aquisição, comparado aos fitorreguladores comumente utilizados no enraizamento de estacas. O zinco é requerido na síntese do triptofano, sendo um precursor do ácido indolacético (hormônio envolvido na formação de raízes adventícias) (BLAKESLEY et al., 1991) e o boro estimula o crescimento das raízes pela influência na translocação de fotoassimilados (MIDDLETON et al., 1980). O uso desse composto para produção de mudas de Platanus $\boldsymbol{x}$ acerifolia Ait. Wild. possibilitou a obtenção de plantas com maior altura e diâmetro de colo, quando propagadas por estacas tratadas com $7,5 \mathrm{~mL} \mathrm{~L}^{-1}$ do produto. Por outro lado, a utilização da dose de $12,5 \mathrm{~mL}$ $\mathrm{L}^{-1}$ do produto propiciou resultados negativos para os mesmos parâmetros avaliados (HOPPE et al., 2005).

O objetivo deste trabalho foi verificar o potencial de enraizamento de estacas de Sebastiania schottiana tratadas com diferentes doses e tempos de embebição em produto comercial Orgasol ${ }^{\circledR}$ FTS (composto por aminoácidos e micronutrientes).

\section{MATERIAL E MÉTODOS}

O material vegetal constituiu-se de ramos obtidos de Sebastiania schottiana localizadas às margens do Rio Soturno, situado nas regiões fisiográficas do Planalto e Depressão Central do Rio Grande do Sul, sob coordenadas geográficas $29^{\circ} 14^{\prime} 07^{\prime \prime}$

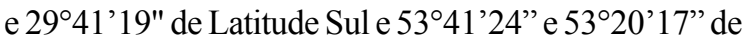
Longitude Oeste. As plantas possuíam idade aproximada de cinco anos, conforme análise dos anéis de crescimento realizada no laboratório de Anatomia Vegetal do Departamento de Ciências Florestais da Universidade Federal de Santa Maria (UFSM). Dois experimentos foram realizados no Viveiro Florestal do Departamento de Ciências Florestais. O cultivo das estacas foi realizado em sacos plásticos $(30 \mathrm{x} 15 \mathrm{~cm})$ contendo areia de granulação média. As irrigações ocorreram uma vez por dia, com uso de aspersores automáticos.

No primeiro experimento, ramos foram seccionados em diferentes posições, obtendo-se estacas basais (diâmetro $>2 \mathrm{~cm}$ ), medianas (diâmetro entre 1 e $2 \mathrm{~cm}$ ) e apicais (diâmetro $<1 \mathrm{~cm}$ ) de Sebastiania schottiana, com $30 \mathrm{~cm}$ de tamanho. Posteriormente, as estacas tiveram suas bases embebidas em solução de Orgasol ${ }^{\mathbb{R}} \mathrm{FTS}$ nas doses de $0 ; 5 ; 10 \mathrm{e} 15 \mathrm{~mL} \mathrm{~L}^{-1}$, durante um minuto. O experimento foi realizado em fatorial $3 \times 4$ (tipos de estaca e doses do produto) no delineamento em blocos ao acaso, com três repetições e 20 estacas por parcela. Aos 75 dias da instalação do experimento, avaliou-se a porcentagem de estacas enraizadas, o comprimento e diâmetro da raiz mais longa. Para o segundo experimento, estacas basais e medianas foram tratadas com $15 \mathrm{~mL} \mathrm{~L}^{-1}$ do mesmo produto por $0,15,30$ e 45 minutos. O experimento foi realizado em fatorial $2 \times 4$ (tipos de estaca $\mathrm{x}$ tempo de embebição), no delineamento em blocos ao acaso, com três repetições e 20 estacas por parcela. Aos 150 dias da instalação do experimento, avaliou-se a porcentagem de estacas 
enraizadas, a massa seca de raízes, o comprimento e diâmetro da raiz mais longa, aferido no ponto de emissão da raiz.

Os dados foram submetidos à análise de variância, análise de regressão e as médias dos tratamentos comparadas pelo teste de Tukey, em probabilidade de erro de 5\%. As análises foram realizadas com o auxílio do programa estatístico SOC, desenvolvido pelo Núcleo Tecnológico para Informática na Agricultura NTIA (EMBRAPA, 1997). As curvas de análise de regressão foram ajustadas com o auxílio do programa Origin Pro v. 8.0. Para as análises, os dados de porcentagem foram transformados para arcoseno $\sqrt{x / 100}$ e de contagem, comprimento e diâmetro para $\sqrt{x+0,5}$.

\section{RESULTADOS E DISCUSSÃO}

Para o parâmetro porcentagem de enraizamento não houve interação entre os fatores tipo de estaca e tempo de embebição. Em estacas de Sebastiania schottiana, o aumento da dose de Orgasol ${ }^{\circledR}$ FTS promoveu o crescimento quadrático em todos os parâmetros avaliados (Figura 1). Na sua ausência, somente $18 \%$ das estacas enraizaram, independente do tipo de estaca utilizado. A dose de $15 \mathrm{~mL} \mathrm{~L}^{-1}$ do produto promoveu a maior porcentagem de enraizamento, sendo esse tratamento responsável por um acréscimo de aproximadamente $60 \%$ no número de estacas enraizadas. Esses resultados indicam que a utilização do produto favoreceu a formação e o desenvolvimento de raízes adventícias, podendo esse fato estar relacionado com a presença de peptonas e aminoácidos orgânicos, além de micronutrientes na composição do produto, que atuam como estimuladores do metabolismo, catalisando as reações químicas. Essas substâncias favorecem o transporte e armazenamento de nitrogênio (RSA, 2006) e promovem a translocação dos carboidratos para a área tratada, aumentando a taxa de respiração e a transformação dos carboidratos em compostos nitrogenados orgânicos (KRAMER \& KOZLOWSKI, 1972), diretamente envolvidos nos processos de gênese de novos primórdios radiciais adventícios. Em estacas jovens de ramos em crescimento de Platanus $\boldsymbol{x}$ acerifolia Ait. Wild., tratadas com o mesmo produto empregado neste estudo, foi observado o aumento da sobrevivência das estacas e a obtenção de plantas com maior altura e diâmetro do colo, se comparadas às provenientes de estacas não-tratadas (HOPPE et al., 2005).

Independente das doses do produto utilizadas, as estacas basais de Sebastiania schottiana (Figura 2A) não diferiram significativamente das

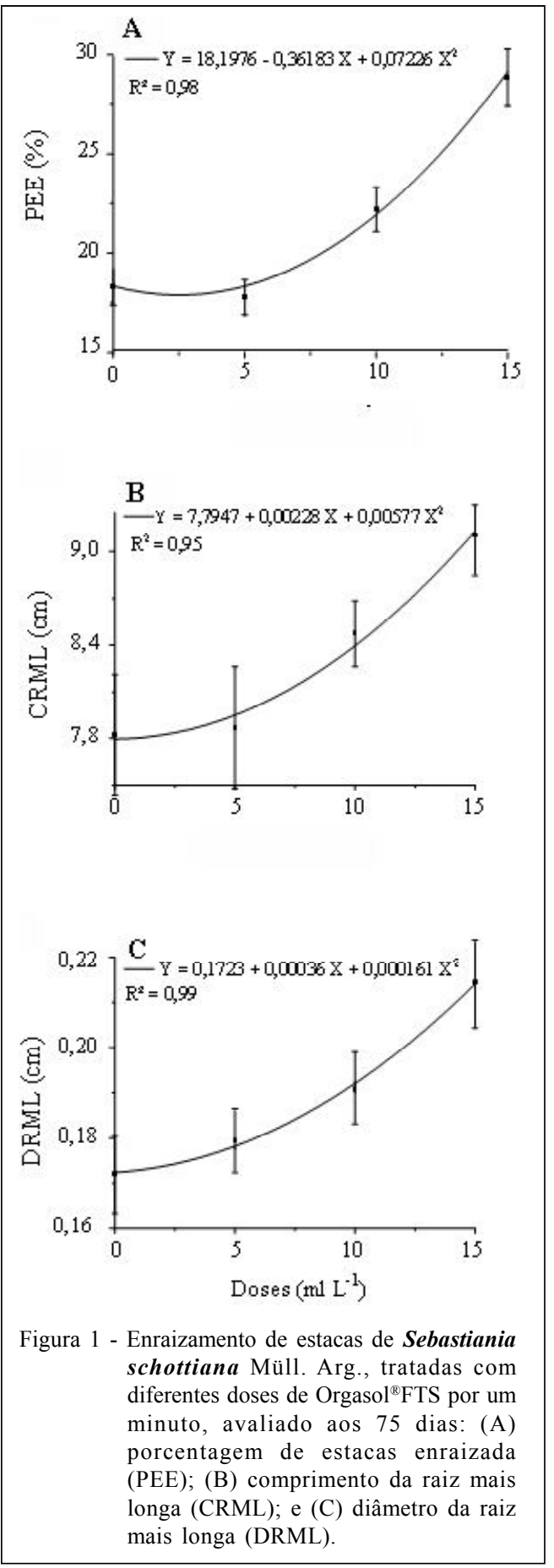

estacas medianas para a porcentagem de estacas enraizadas, que diferiram das estacas apicais (Figuras 3Ae 2B). Também foi observado um maior comprimento da raiz mais longa em estacas basais e medianas e um maior diâmetro da raiz mais longa em estacas medianas, mas sem diferir estatisticamente das estacas basais (Figuras 3B). Esse fato pode indicar que, mesmo com o uso de substâncias que estimulem o metabolismo da 


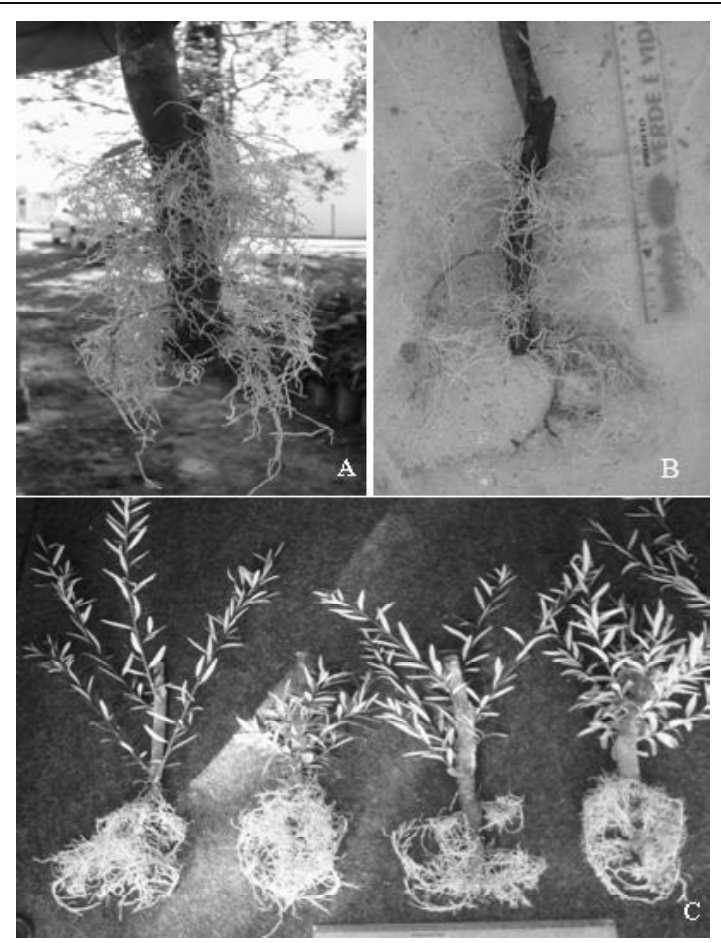

Figura 2 - Enraizamento de estacas de Sebastiania schottiana Müll. Arg., independente das doses de Orgasol ${ }^{\circledR} \mathrm{FTS}$, avaliado aos 75 dias: (A) porcentagem de estacas enraizadas (PEE) e (B) diâmetro médio da raiz mais longa (DRML). Médias não ligadas com as mesmas letras são significativamente diferentes pelo Teste Tukey a $5 \%$ de probabilidade de erro.

planta, a posição das estacas na planta (topófise) pode diferenciar quanto ao conteúdo de auxinas, importantes na rizogênese adventícia; e de carboidratos que servirão como reserva energética e de material para a construção de estruturas celulares necessárias para todos os processos fisiológicos da planta.

No experimento 2 , houve um efeito significativo do tempo de embebição das estacas de Sebastiania schottiana em $15 \mathrm{~mL} \mathrm{~L}^{-1}$ de Orgasol ${ }^{\circledR}$ FTS para todos os parâmetros avaliados. A porcentagem de estacas basais e medianas enraizadas aumentou sensivelmente à medida que houve um acréscimo no tempo de embebição nessa solução (Figura 4A). Na sua ausência, foi observado $29 \%$ de estacas medianas enraizadas e $25 \%$ de estacas basais e, no tratamento por 45 minutos, ocorreu um aumento para $46 \%$ de estacas medianas enraizadas e $36 \%$ de estacas basais. Para ambos os tipos de estacas, a massa seca de raízes apresentou um incremento em função do aumento do tempo de embebição em $15 \mathrm{ml} \mathrm{L}^{-1}$ do produto (Figura 4B).

Para as estacas basais e medianas, o comprimento da raiz mais longa teve um comportamento

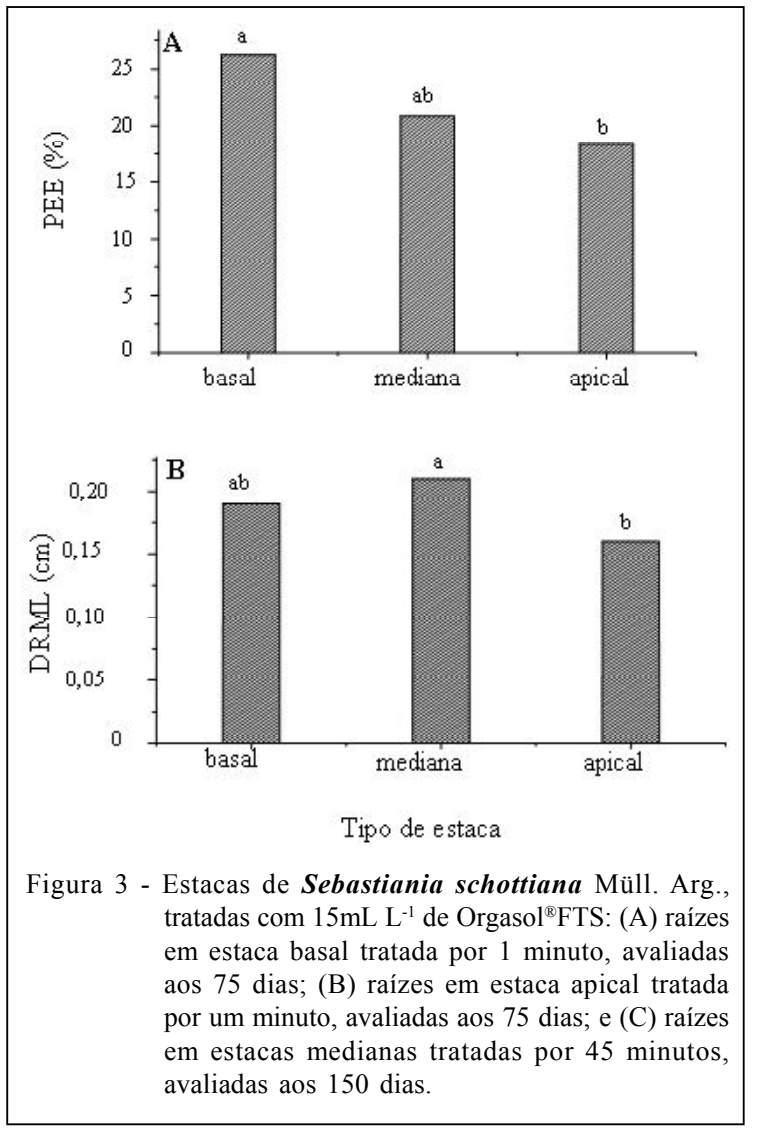

diferente em relação ao tempo de embebição em $15 \mathrm{~mL}$ $\mathrm{L}^{-1}$ do produto. As raízes das estacas medianas, sem a utilização do produto, atingiram $12,4 \mathrm{~cm}$, enquanto que, em estacas tratadas durante 45 minutos (Figura 2C), obteve-se 14,3cm (Figura 5A). Já nas estacas basais, foi observado que a utilização do produto inibiu o comprimento da raiz mais longa. Para o parâmetro diâmetro da raiz mais longa, praticamente não houve variação quando se aumentou o tempo de embebição em solução de $15 \mathrm{~mL} \mathrm{~L}^{-1}$ do produto, tanto nas raízes formadas em estacas medianas quanto em estacas basais (Figura 5B).

O aumento do tempo de embebição em solução de $15 \mathrm{~mL} \mathrm{~L}^{-1}$ de Orgasol $^{\circledR}$ FTS favoreceu a formação de raízes em estacas basais e medianas de Sebastiania schottiana, indicando que o $\operatorname{Orgasol} \mathrm{l}^{\mathbb{B}}$ FTS possa ter contribuído na elevação dos teores de carboidratos e substâncias promotoras do enraizamento das estacas. Além disso, os aminoácidos podem, juntamente com os íons $\mathrm{Zn}$ e B, terem estimulado o desenvolvimento radicular. 


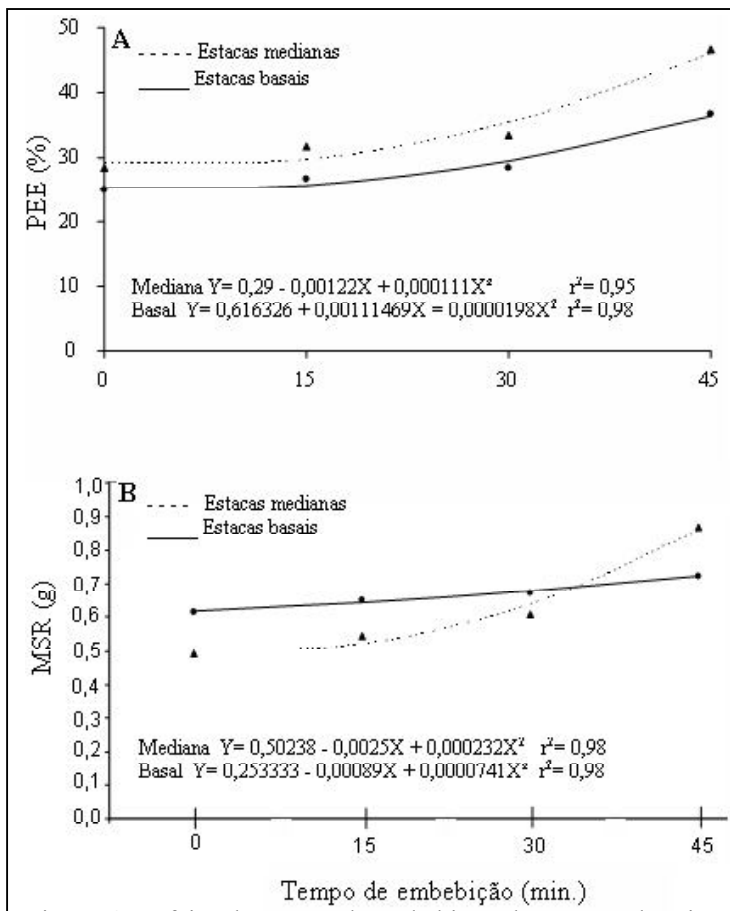

Figura 4 - Efeito do tempo de embebição das estacas basais e medianas de Sebastiania schottiana Müll. Arg. em solução de Orgasol $^{\mathbb{R}}$ FTS $\left(15 \mathrm{~mL} \mathrm{~L}^{-1}\right)$, aos 150 dias de avaliação: (A) porcentagem de estacas enraizadas (PEE) e (B) massa seca de raízes (MSR).

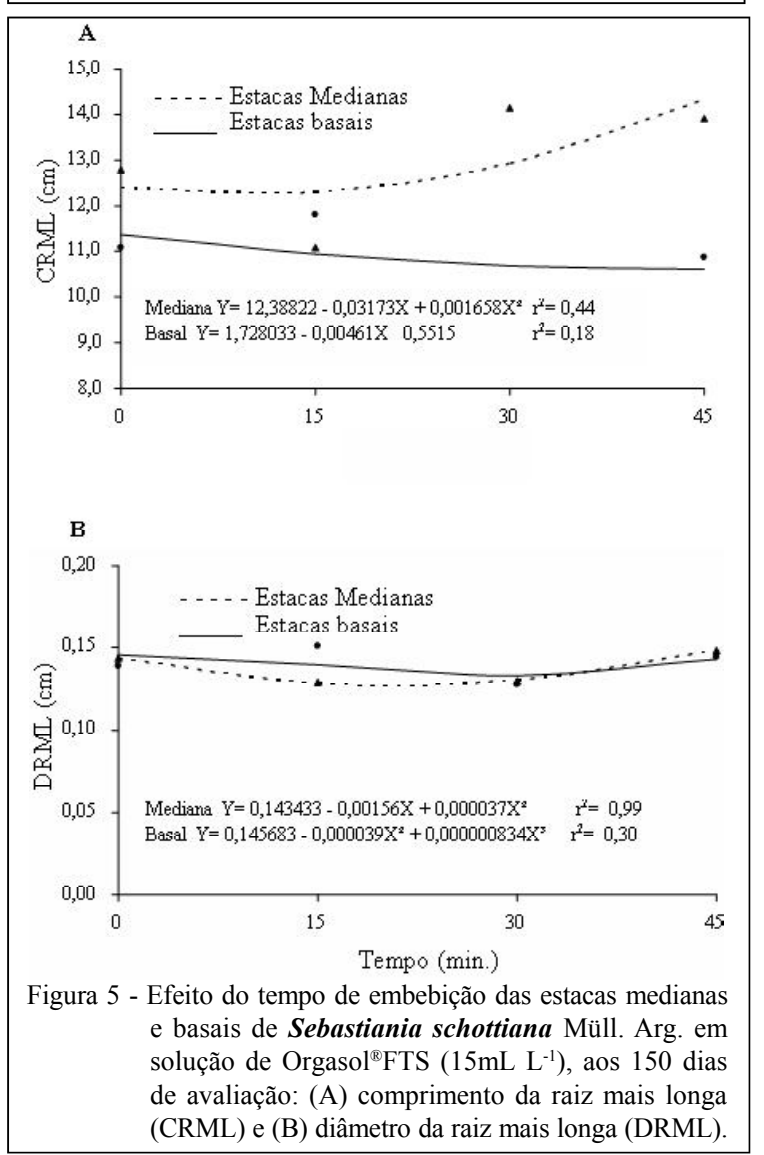

\section{CONCLUSÃO}

Estacas basais e medianas de Sebastiania schottiana tratadas com $15 \mathrm{~mL} \mathrm{~L}^{-1}$ de Orgasol ${ }^{\circledR}$ FTS apresentaram maior potencial de enraizamento. $\mathrm{O}$ aumento do tempo de imersão das estacas em $15 \mathrm{~mL} \mathrm{~L}^{-1}$ de Orgasol ${ }^{\circledR}$ FTS por 45 minutos favoreceu a indução de raízes adventícias.

\section{REFERÊNCIAS}

BLAKESLEY, D. et al. The role of endogenous auxin em root initiation. Plant Growth Regulation, Dordrecht, v.10, p.341353, 1991. Disponível em: <http://dx.doi.org/10.1007/ BF00024593>. Acesso em: 01 abr. 2010. doi: 10.1007/ BF00024593.

BRANDÃO, R.P. Importância dos aminoácidos na agricultura sustentável. Disponível em: <http:// www.biosoja.com.br/downloads/Informativo\%205.pdf>. Acesso em: 24 out. 2010.

DESCHAMPS, C.; PINTO, J.E.B.P. Enraizamento in vitro de microestacas e micropropagação de gemas axilares de sarandi (Sebastiania schottiana Müell. Arg.). Ciência Rural, Santa Maria, v.25, n.3, p.389-393, 1995.

EMBRAPA. Centro Nacional de Pesquisa Tecnológica em Informática para Agricultura. Ambiente software NTIA, versão 4.2.2: Manual do usuário - Ferramental estatístico. Campinas: EMBRAPA/SEI, 1997. 258p.

GONDIM, T.M.S. et al. Efeito da porção do ramo e comprimento de estacas na propagação vegetativa de plantas de cupuaçu. Revista Brasileira de Fruticultura, Jaboticabal, v.23, n.1, p.203-205, 2001.

HARTMANN, H.T. et al. Plant propagation: principles and practices. 7.ed. New Jersey: Prentice Hall, 2002. 880p.

HOPPE, J.M. et al. Uso do bacsol e orgasol como enraizantes na produção de mudas de Platanus $x$ acerifolia. Santa Maria: Centro Tecnológico de Silvicultura, Universidade Federal de Santa Maria, 2005. 78p. (Relatório Técnico).

KRAMER, P.J.; KOZLOWSKI, T.T. Fisiologia das árvores. Lisboa: Fundação Calouste Gulbenkian, 1972. 745p.

MARCHIORI, J.N.C. Dendrologia das Angiospermas: das Bixáceas às Rosáceas. Santa Maria: UFSM, 2000. 240p.

MIDDLETON, W. et al. The role of leaves in auxin and boro dependent rooting of stem cuttings of Phaseolus aureus Roxb. New Phytologist, Cambridge, v.84, p.251-259, 1980.

REITZ, P.R. Euphobiaceas. In: REITZ, P.R. (Ed.). Flora ilustrada catarinense. Itajaí: Herbáreo Barbosa Rodrigues, 1988. 156p.

RSA. Indústria de Insumos Agrícolas LTDA. Produto Orgasol ${ }^{\circledR}$. São Paulo, 2006. 8p. (Informativo Técnico).

Ciência Rural, v.40, n.12, dez, 2010. 